\title{
The retinoic acid-inactivating enzyme CYP26 is essential for establishing an uneven distribution of retinoic acid along the anterio-posterior axis within the mouse embryo
}

\author{
Yasuo Sakai, ${ }^{1}$ Chikara Meno, ${ }^{1}$ Hideta Fujii, ${ }^{1}$ Jinsuke Nishino, ${ }^{1}$ Hidetaka Shiratori, ${ }^{1}$ Yukio Saijoh, ${ }^{1}$ \\ Janet Rossant, ${ }^{2}$ and Hiroshi Hamada ${ }^{1,3}$ \\ ${ }^{1}$ Division of Molecular Biology, Institute for Molecular and Cellular Biology, Osaka University, and Core Research for \\ Evolutional Science and Technology, Japan Science and Technology Corporation, Osaka 565-0871, Japan; ${ }^{2}$ Samuel Lunenfeld \\ Research Institute, Mount Sinai Hospital, Toronto, Ontario, M5G 1X5, Canada
}

Retinoic acid (RA), a derivative of vitamin A, plays a pivotal role in vertebrate development. The level of RA may be determined by the balance between its synthesis and degradation. We have examined the role of CYP26, a P450 enzyme that may degrade RA, by generating mutant mice that lack CYP26. CYP26 ${ }^{-/-}$mice exhibited anomalies, including caudal agenesis, similar to those induced by administration of excess RA. The concentration of endogenous RA, as revealed by marker gene activity, was markedly increased in the tailbud of the mutant animals, in which CYP26 is normally expressed. Expression of T (Brachyury) and Wnt3a in the tailbud was down-regulated in $\mathrm{CYP}^{-1-}$ mice, which may underlie the caudal truncation. The lack of CYP26 also resulted in homeotic transformation of vertebrae as well as in misspecification of the rostral hindbrain associated with anterior expansion of RA-positive domains. These results suggest that local degradation of RA by CYP26 is required for establishing an uneven distribution of RA along the anterio-posterior axis, which is essential for patterning the hindbrain, vertebrae, and tailbud.

[Key Words: CYP26; hindbrain; Hox; retinoic acid]

Received September 18, 2000; revised version accepted December 6, 2000.

Retinoic acid (RA), the active metabolite of vitamin A, plays critical roles in normal embryonic development (for review, see Conlon 1995; Maden 1999). Deficiency in vitamin A results in a spectrum of malformations collectively known as the fetal vitamin A deficiency syndrome. Conversely, intake of excess RA during pregnancy leads to a wide array of developmental defects. RA exerts its effects by serving as a ligand for nuclear receptors called RARs and RXRs. In the presence of RA, an RAR-RXR homodimer or heterodimer can regulate expression of a set of genes.

The role of RA in embryogenesis has been studied by generating mutant mice lacking RAR or RXR, but this was confounded by the presence of multiple receptors that may function redundantly. Thus, mutations in a single receptor gene resulted in no or only subtle anomalies, whereas compound mutants exhibited more severe defects and recapitulated the phenotypes of the fetal vi-

${ }^{3}$ Corresponding author.

E-MAIL hamada@imcb.osaka-u.ac.jp; FAX 81-6-6878-9846.

Article and publication are at www.genesdev.org/cgi/doi/10.1101/gad. 851501 . tamin A deficiency syndrome (Kastner et al. 1995). Mutant mice lacking an RA-synthesizing enzyme Raldh2 are devoid of RA and show severe developmental defects (Niederreither et al. 1999). However, the early death of Raldh2 mutant embryos prevented deduction of the role that RA plays at later stages. In fact, there are many developmental processes that are thought to be mediated by RA. For example, RA has been implicated in specifying the zone of polarizing activity in the limbud (Helms et al. 1996) and in specifying the identity of spinal motor neurons (Sockanathan and Jessell 1998). The role of RA in these processes is yet to be established.

Animal cells cannot produce RA de novo; they ingest them in the form of provitamin A carotenoids and retinyl esters, which are converted to retinol in the intestine. Retinol is further metabolized, via retinal, to RA. Some of the enzymes that catalyze these reactions have been characterized. A good example is Raldh2, an enzyme that converts retinal to RA (Wang et al. 1996; Zhao et al. 1996). RA is also subjected to degradation in vivo. Thus, the level of RA concentration in our body is regulated by the rate of its synthesis and degradation. 
Sakai et al.

CYP26 (also known as P450RA) is a P450 enzyme that metabolizes RA (White et al. 1996; Fujii et al. 1997; Ray et al. 1997; Hollemann et al. 1998). Overexpression of CYP26 in cultured cells renders them hyposensitive to RA (Fujii et al. 1997). Microsome fractions containing CYP26 can metabolize RA in vitro into oxidative forms such as 5,8-epoxy RA (Fujii et al. 1997), 4-hydroxy RA, and 18-hydroxy RA (White et al. 1996). These previous observations suggested that CYP26 may be an enzyme that degrades RA in vivo. The balance between RA synthesis by Raldh2 and its degradation by CYP26 may determine the concentration of active RA in a given cell. CYP26 may also determine the distribution of RA within an embryo. In fact, it has been suggested that some embryonic domains (such as the node and floor plate) contain a higher level of RA than others (Chen et al. 1992). Furthermore, CYP26, as well as Raldh2, is expressed in a stage- and region-specific fashion during development (Fujii et al. 1997; Niederreither et al. 1997; McCaffery et al. 1999; Swindell et al. 1999). Interestingly, expression domains of CYP26 and Raldh2 are largely complementary; for example, CYP26 is expressed in the tailbud and rostral hindbrain when Raldh2 is expressed in the trunk region. Such complementary expression domains of CYP26 and Raldh2 may be able to establish an uneven distribution of RA within an embryo.

In this study, we have examined the role of CYP26 in RA metabolism and in embryogenesis by generating mutant mice lacking CYP26. The CYP26 mutant mice exhibited elevation of RA in the domains in which CYP26 is normally expressed, establishing that CYP26 degrades active RA. The lack of CYP26 impaired the distribution of RA along the anterio-posterior (A-P) axis, and resulted in abnormal patterning of the hindbrain, vertebrae, and tailbud. Thus, CYP26 is essential for establishing an uneven distribution of RA along the A-P axis.

\section{Results}

\section{CYP26 mutant mice are embryonic or neonatal lethal}

To investigate the roles of CYP26 in RA metabolism and embryogenesis, we subjected the mouse CYP26 locus to targeted disruption. Two mutant alleles were generated as follows: A null allele $\left(C Y P 26^{-}\right)$, in which all of the exons were deleted, and a hypomorphic allele $\left(C Y P 26^{\text {neo }}\right)$, in which the neo gene was inserted into the 3 '-flanking region (Fig. 1). In the present study, we describe mostly the analysis of the mutant mice generated with the null allele.

The CYP26+/- heterozygotes appeared grossly normal and were fertile. Intercrossing of these heterozygotes resulted in the birth of $\mathrm{CYP}^{-/-} 6^{-1}$ mice, but most of these animals died within 1 day. Although the precise phenotype varied among individual animals, the most common features of $C Y P 26^{-/-}$mice were caudal truncation, vertebra transformation, and hindbrain misspatterning (Table 1). Externally, CYP26-/- mice exhibited a mermaid-like deformity (sirenomelia), with the caudal part of the body severely truncated and the anterior portion remaining relatively normal (Fig. 2A,B) The hind limbs were typically fused at the midline and the tail was missing. Spina bifida (Fig. 2D) was also apparent. Postmortem examination of abdominal organs of $C Y P 26^{-/-}$mice revealed aplasia or hypoplasia of the urogenital system, including the kidneys. The posterior end of the hindgut

\section{A}

Figure 1. Generation of CYP26 mutant mice. (A) Targeting strategy. Homologous recombination between the wild-type CYP26 allele (exons are shown as solid boxes) and the targeting vector generates an insertional allele (CYP26 $\left.{ }^{\text {neo }}\right)$. A null allele $\left(C Y P 26^{-}\right)$was created by subsequent Cre-mediated deletion of the indicated region located between lox $\mathrm{P}$ sites. (C) ClaI; (N) NsiI; (RV) EcoRV; (S) SalI; (X) XhoI; (DT) a diphtheria toxin-resistance cassette. (B) Southern blot analysis of offspring obtained from intercrossing of CYP26 ${ }^{\text {neo/+ }}$ heterozygotes. Genomic DNA were digested with both NsiI and ClaI, and EcoRV, the resulting fragments were subjected to hybridization with the $5^{\prime}$ probe and the $3^{\prime}$ probe indicated in $A$, respectively. The sizes of hybridizing fragments are indicated in kilobases. (C) PCR analysis with a mixture of the three primers (P1, $\mathrm{P} 2$, and $\mathrm{P} 3$ ) shown in $A$ of offspring obtained from intercrossing of $C Y P 26^{+/-}$heterozygotes. The sizes of PCR products are shown in base pairs.

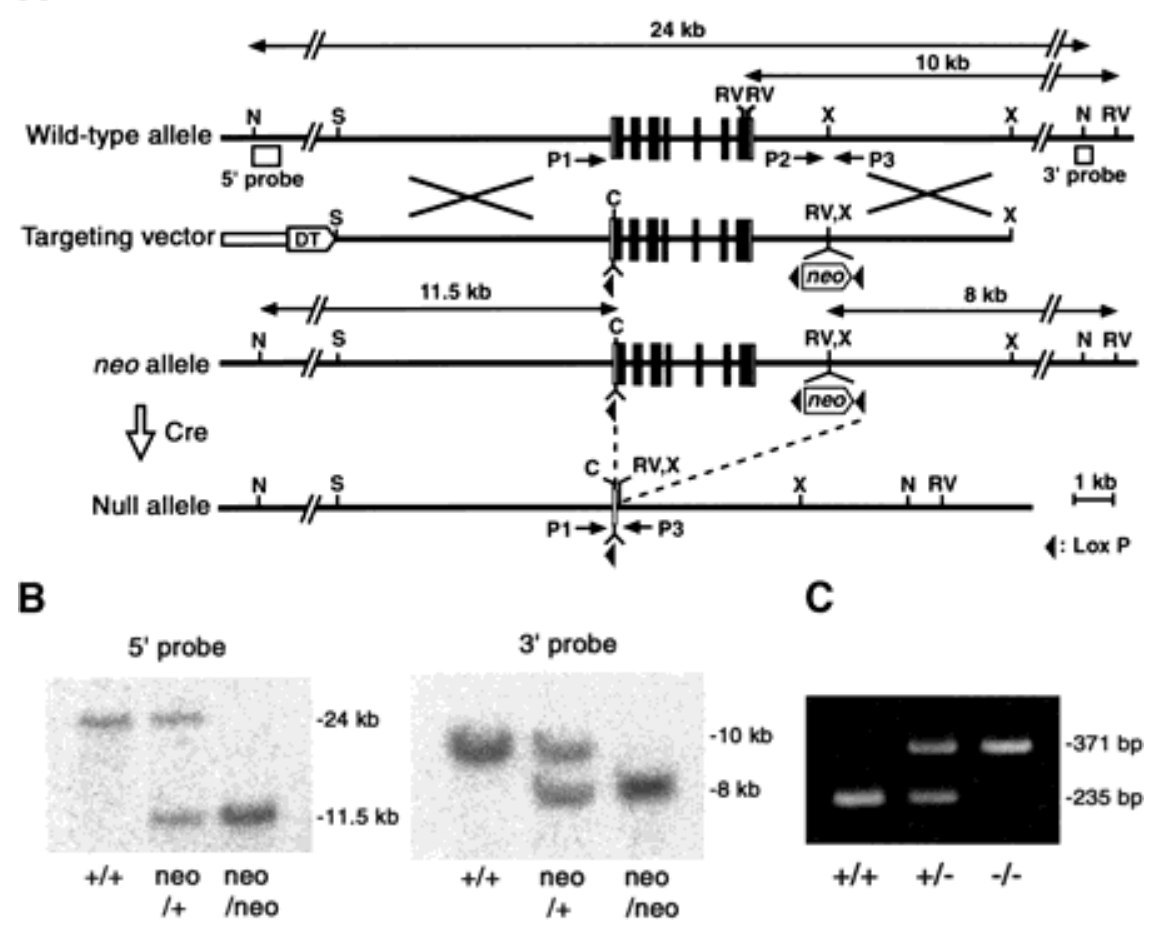


Table 1. Various defects detected in postnatal CYP26 mutant mice

\begin{tabular}{|c|c|c|c|c|c|c|c|}
\hline No. & Short tail & Spina bifida & Sirenomelia & $\begin{array}{l}\text { Deficiency of } \\
\text { the external genitalia }\end{array}$ & Anal atresia & Horseshoe kidney & Skeletal analysis \\
\hline 1 & $\mathrm{X}$ & $\mathrm{X}$ & $\mathrm{X}$ (aplasia) & $\mathrm{X}$ & $\mathrm{X}$ & $\mathrm{X}$ & 2 \\
\hline 2 & $\mathrm{X}$ & $\mathrm{X}$ & $\mathrm{X}$ & $\mathrm{X}$ & $\mathrm{X}$ & $\mathrm{X}$ & 1 \\
\hline 3 & $\mathrm{X}$ & $\mathrm{X}$ & $\mathrm{X}$ & $\mathrm{X}$ & $\mathrm{X}$ & $\mathrm{X}$ & 3 \\
\hline 4 & $\mathrm{X}$ & $\mathrm{X}$ & $\mathrm{X}$ & $\mathrm{X}$ & $\mathrm{X}$ & $\mathrm{X}$ & 4 \\
\hline 5 & $\mathrm{X}$ & $\mathrm{X}$ & $\mathrm{X}$ & $\mathrm{X}$ & $\mathrm{X}$ & $\mathrm{X}$ & ND \\
\hline 6 & $\mathrm{X}$ & $\mathrm{X}$ & $\mathrm{X}$ & $\mathrm{X}$ & $\mathrm{X}$ & $\mathrm{X}$ & ND \\
\hline 7 & $\mathrm{X}$ & $\mathrm{X}$ & - & - & - & $\mathrm{X}$ & 5 \\
\hline 8 & $\mathrm{X}$ & $\mathrm{X}$ & - & - & - & - & ND \\
\hline 9 & $\mathrm{X}$ & $\mathrm{X}$ & - & - & - & - & ND \\
\hline 10 & $\mathrm{X}$ & - & - & - & - & - & ND \\
\hline
\end{tabular}

Ten CYP26 mutant mice obtained postnataly were examined. (X) Phenotype observed; (-) phenotype not observed; (ND) not determined. The mice referred to as 1 to 5 correspond to the animals 1 to 5 in Fig. 5G.

was often terminated as an appendix (Fig. 2E). Histological analysis of embryos confirmed the aplasia or hypoplasia of the urogenital system (Fig. 2F,G). The kidneys were often fused, resulting in the development of horseshoe kidney (Fig. 2F). The CYP26 $6^{\text {neo/neo }}$ mice appeared normal, whereas CYP26 $6^{\text {neo/- }}$ mice exhibited a subtle phenotype characterized by a short or kinky tail (Fig. $2 \mathrm{G})$, indicating that $C Y P 26^{\text {neo }}$ is a weak hypomorphic allele.

The frequency of CYP26-/- mice at birth was smaller than expected (Table 2), suggesting that more than twothirds of these animals die in utero. To characterize the embryonic lethality of the null allele in the homozygous state, we analyzed litters produced from intercrosses of heterozygotes.

Homozygous mutant embryos were detected at the expected frequency at embryonic day (E) 9.5 and appeared morphologically normal until E8.5 (data not shown). Morphological abnormalities were first apparent at E9.5, when all $(25 / 25)$ of the CYP26 $6^{-1-}$ embryos exhibited posterior truncation with $(18 / 25)$ or without $(7 / 25)$ the failure of anterior neural tube closing. More severely affected embryos (10/25) manifested additional defects such as irregular folding of the neural tube, irregular somites, incomplete axial turning, and heart abnormalities. Between E12.5 and E18.5, the mutant embryos developed caudal truncation (a severe example is shown in Fig. 2C), and some (3/13) also exhibited exencephaly.

Elevation of RA level and down-regulation of Brachury and Wnt3a in the tailbud lead to the caudal truncation

To understand the molecular basis of the caudal truncation apparent in $C Y P 26^{-1-}$ mice, we first examined the expression of an RA-responsive transgene (RAREhsplacZ), which consists of three RA response elements linked to the hsp 68 promoter and lacZ gene and which reveals the transactivation activity of endogenous RA (Rossant et al. 1991). In wild-type embryos, the level of CYP26 expression appeared inversely related to that of
RARE-hsplacZ expression. At E7.75, when CYP26 expression was confined to the anterior region (Fig. 3A) expression of the lac $Z$ transgene was marked in the posterior region (Fig. 3E). When CYP26 expression begins in the tailbud at E8.25 (Fig. 3B,C), the tailbud starts to lose lacZ expression (Fig. 3F,G). At E8.5 to E9.0, when CYP26 expression in the tailbud is maximal (Fig. 3D), transgene expression is absent from the entire tailbud (Fig. $3 \mathrm{H}$ ). In CYP26 ${ }^{-1-}$ embryos, however, the RARE-hsplacZ transgene continues to be expressed in the tailbud at E8.25 and E9.0 (Fig. 3J-L), indicating that the lack of CYP26 results in an increased concentration of RA.

We next examined the expression of $T$ (Brachyury) and Wnt3 $a$ at E9.0. In wild-type embryos, $T$ was expressed in the caudal streak and notochord at this stage (Fig. 4A,B) In E9.0 CYP26 $6^{-/-}$embryos, however, $\mathrm{T}$ expression in the posterior mesoderm and neural plate was markedly down-regulated (Fig. 4D,E). The expression of $T$ in the notochord was largely preserved, but it always bifurcated in the posterior region (Fig. 4D,E). The expression of Wnt3a was also reduced in the tailbud of mutant embryos at E9.0 (Fig. 4F) compared with that in wild-type embryos (Fig. 4C). Interestingly, Wnt3a mutant and T/T mutant embryos also exhibit similar caudal truncation accompanied by excessive neural tube formation at the expense of mesoderm (Wilkinson et al. 1990; Takada et al. 1994; Yoshikawa et al. 1997; Yamaguchi et al. 1999). Furthermore, the expression of both Wnt $3 a$ and $T$ is down-regulated by the administration of excess RA (Iulianella et al. 1999; Wasiak and Lohnes 1999), raising a possibility that the axial truncation in the CYP26 $6^{-1-} \mathrm{mu}-$ tants is due to reduced expression of $T$ and Wnt3a. To investigate this possibility, we examined the neural tube of the mutant mice at E9.5 (Fig. 5) Expression domains of Sox2 (a marker for neural tissue; Kamachi et al. 1998; Wood and Episkopou 1999) were markedly expanded in the caudal region of CYP26 ${ }^{-/-}$embryos (Fig. 5D,E), indicating overproliferation of neural tissue. Ectopic neural structures were also formed in the trunk region of the mutant embryos (Fig. 5F,G). In addition, the neural tube was irregularly folded throughout the anterior-posterior axis (Fig. 5C). These results suggest that the combined 
Sakai et al.
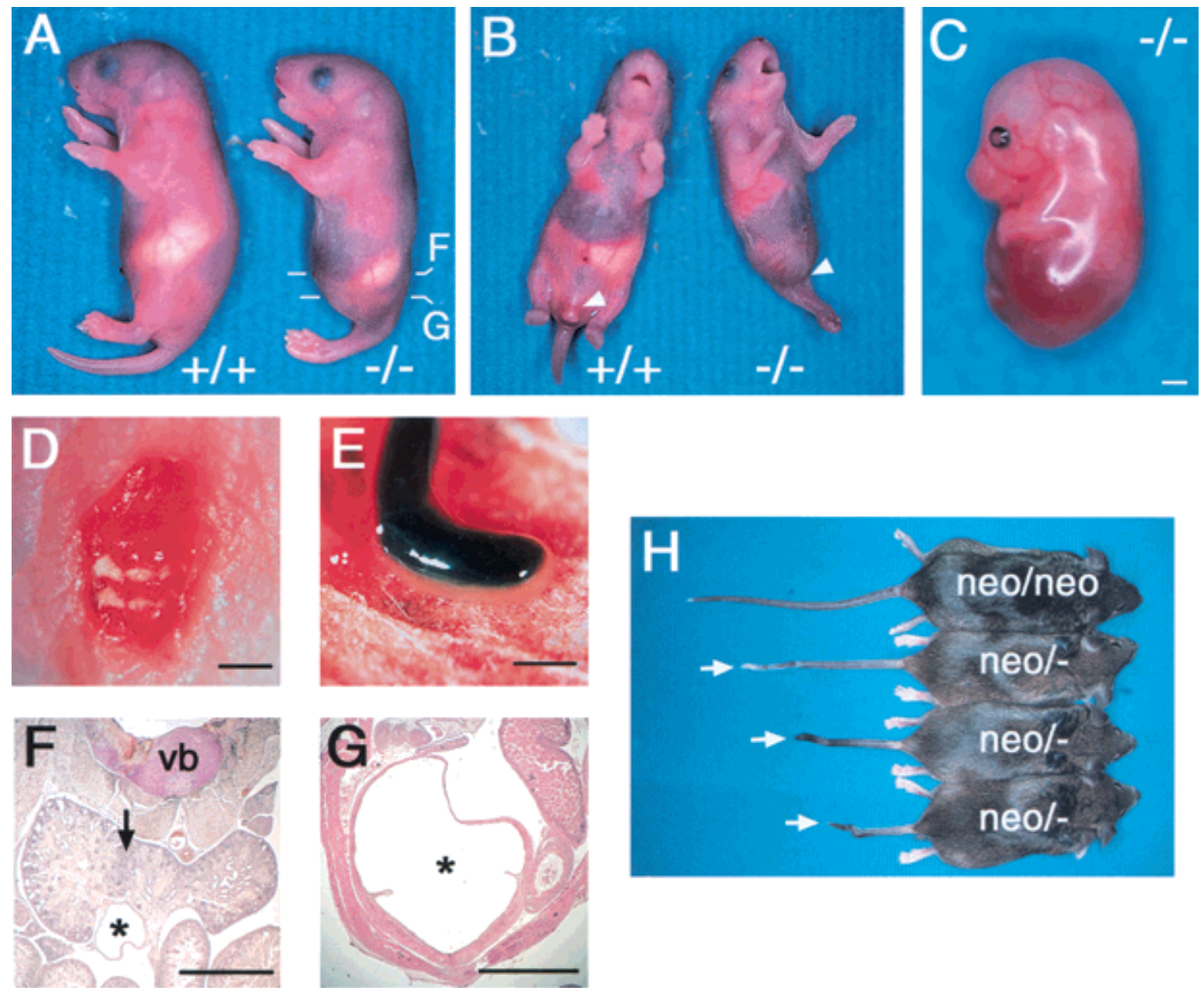

Figure 2. Caudal truncation in CYP26 mutant mice. (A) Wild-type $(+/+)$ and $C Y P 26^{-/-}$mice at postnatal day $(\mathrm{P}) 1$, with the mutant exhibiting sirenomelia. The levels of the sections shown in $F$ and $G$ are indicated. $(B)$ Ventral view of wild-type and $C Y P 26^{-/-}$mice at P1. The mutant exhibits sirenomelia and lacks external genitalia (arrowhead). (C) Lateral view of an E16.5 CYP26-/- embryo completely lacking hind limbs and a tail. $(D)$ Dorsal view of a homozygous mutant embryo at P1 exhibiting spina bifida. $(E)$ Atresia of the gut in a $C Y P 26^{-/-}$embryo at P1. (F,G) Histological examination of the abdomen of a CYP26 $6^{-/-}$mouse at P1. Horseshoe kidney (arrow) and a fused ureter (asterisk) are apparent in $F$. The abnormally dilated bladder (asterisk) apparent in $G$ connects to the ureter shown in F. (vb) Vertebra body. (H) CYP26 $6^{\text {neo/neo }}$ and $C Y P 26^{\text {neo/- }}$ mice at 8-10 wk after birth. Various types of kinky tail (arrows) are apparent in the $C Y P 26^{\text {neo/- }}$ animals. Scale bar, $1 \mathrm{~mm}$ for $C-G$.

down-regulation of Wnt3a and $T$ in the tailbud, which is induced by an increase in the concentration of RA, is likely responsible for the severe axial truncation apparent in the $\mathrm{CYP26} 6^{-/-}$mice.

Table 2. Litters obtained by crossing of $\mathrm{CYP} 26^{+/-}$mice

\begin{tabular}{lcccc}
\hline & \multicolumn{3}{c}{ Genotype } & \\
\cline { 2 - 4 } Stage & $+/+$ & $+/-$ & $-/-$ & Total \\
\hline E9.5 & 23 & 45 & 25 & 93 \\
E12.5-18.5 & 20 & 39 & $13(6)$ & 72 \\
Postnatal & 33 & 80 & $10(6)$ & 123 \\
& $(26.8 \%)$ & $(65.6 \%)$ & $(8.1 \%)$ & $(100 \%)$ \\
\hline
\end{tabular}

The numbers of dead animals/embryos at the time of observation are shown in parentheses.
Homeotic transformation of vertebrae accompanied by elevation of RA level in the somites

Skeletal defects were also evident in the homozygous mutants. As expected from the external appearance of these mice, the lumbar, sacral, and caudal vertebrae were missing, and the hind limb bones (femur and tibia) were fused at the midline (Fig. 6D). The CYP26 $6^{-/-}$mice also exhibited homeotic transformation of vertebrae. The wild-type mice have 13 thoracic vertebrae (from T1 to T13), each of which possesses a rib. In the CYP26 $6^{-/-}$ mice, however, there were 15 vertebrae harboring a rib (among 5 mutant mice analyzed, we first describe the most severe case, animal 1 in Fig. 6G). Of seven cervical vertebrae of the mutant mice $\left(\mathrm{C} 1^{*}\right.$ to $\mathrm{C}^{*}$, with the asterisk indicating the CYP26-/- mutant), the distal portion of $\mathrm{Cl}^{\star}$ was split into two branches $\left(\mathrm{Cla}^{\star}\right.$ and $\left.\mathrm{Clb}^{\star}\right)$, 


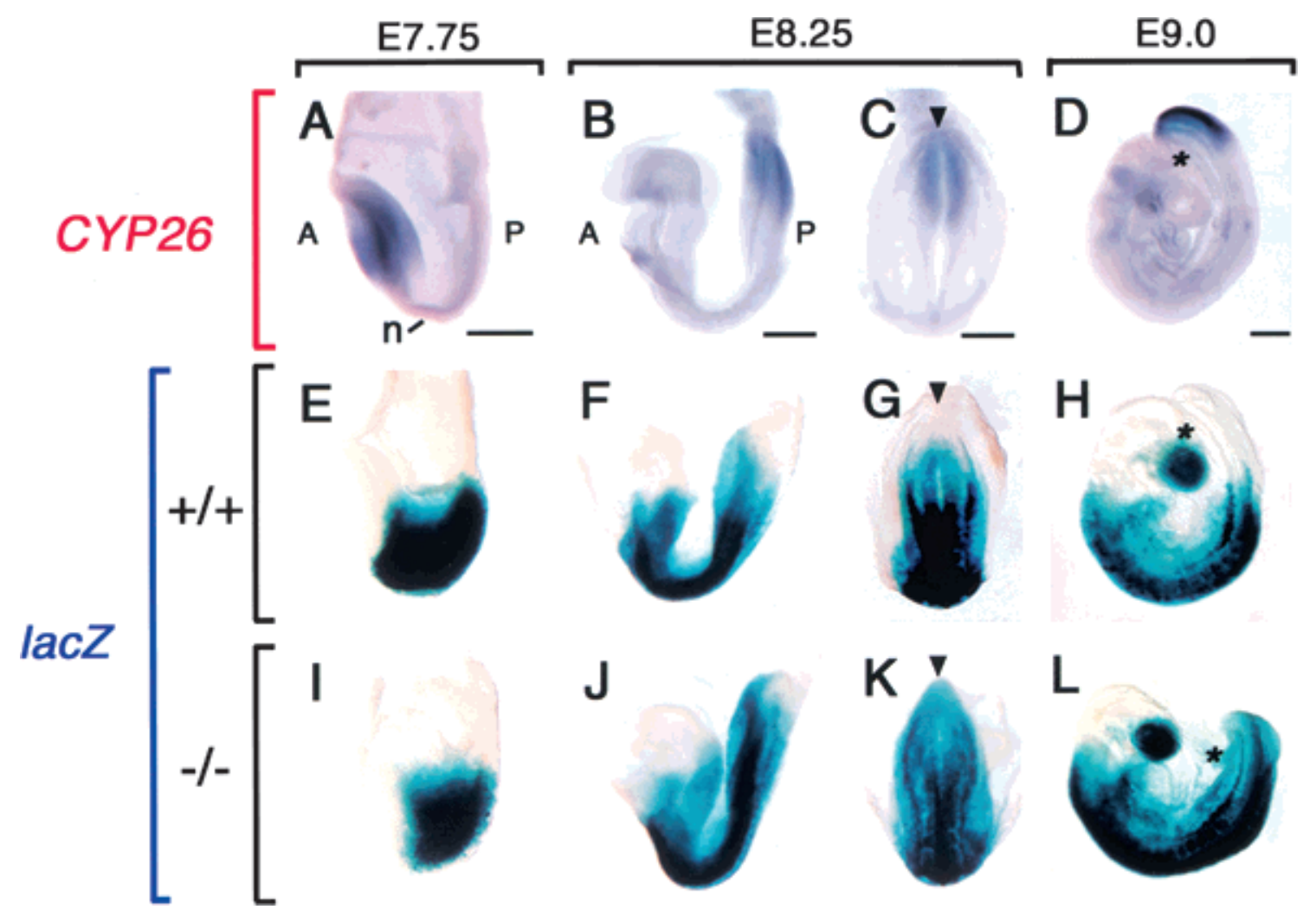

Figure 3. Correlation between CYP26 expression and the level of endogenous RA in the tailbud. $(A-D)$ Expression of $C Y P 26$ in wild-type embryos at E7.75, E8.25, and E9.0, respectively. Expression of the RARE-hsplacZ transgene in wild-type $(E-H)$ and $C Y P 26^{-/-}$ $(I-J)$ embryos. X-gal staining extends to the caudal end of the mutant embryos. (A) Anterior; $(\mathrm{P})$ posterior; $(\mathrm{n})$ node. The arrowhead $(C, G, K)$ indicates a position of the caudal end and the asterisk $(D, H, L)$ indicates the base of the allantois. Scale bar, $300 \mu m$.

whereas the main portion of $\mathrm{C} 1{ }^{\star}$ had the anterior arch of atlas that is unique to $\mathrm{C} 1$ (Fig. 6E). The $\mathrm{Cla}$ * branch was fused to the exoccipital bone, whereas $\mathrm{C}^{\star} b^{\star}$ was morphologically similar to the dorsal arch of C2. C2 ${ }^{\star}$ possessed the dens of $\mathrm{C} 2$, but its dorsal arch resembled that of C3 (Fig. 6E). C5* exhibited the anterior tubercle characteristic of $\mathrm{C} 6$, whereas $\mathrm{C}^{\star}{ }^{\star}$ possessed a rib, a characteristic normally associated with T1 (Fig. 6E). These morphological features suggested that all of the cervical vertebrae were posteriorly transformed from C1, C2, C3, C4, C5, C6, and C7 to C1-C2, C2-C3, C4, C5, C6, C7, and $\mathrm{T} 1$, respectively. The thoracic vertebrae of the CYP26 $6^{-1-}$ mice $\left(\mathrm{T}^{\star}{ }^{\star}-\mathrm{T} 13^{\star}\right)$ were often deformed and their ribs were fused (Fig. 6F). The twenty-first vertebra of the mutant mice $\left(\mathrm{L}^{\star}{ }^{\star}\right)$ possessed a small rib (Fig. $\left.6 \mathrm{~F}\right)$, indicating that $\mathrm{L} 1$ had been transformed into a T13 iden-

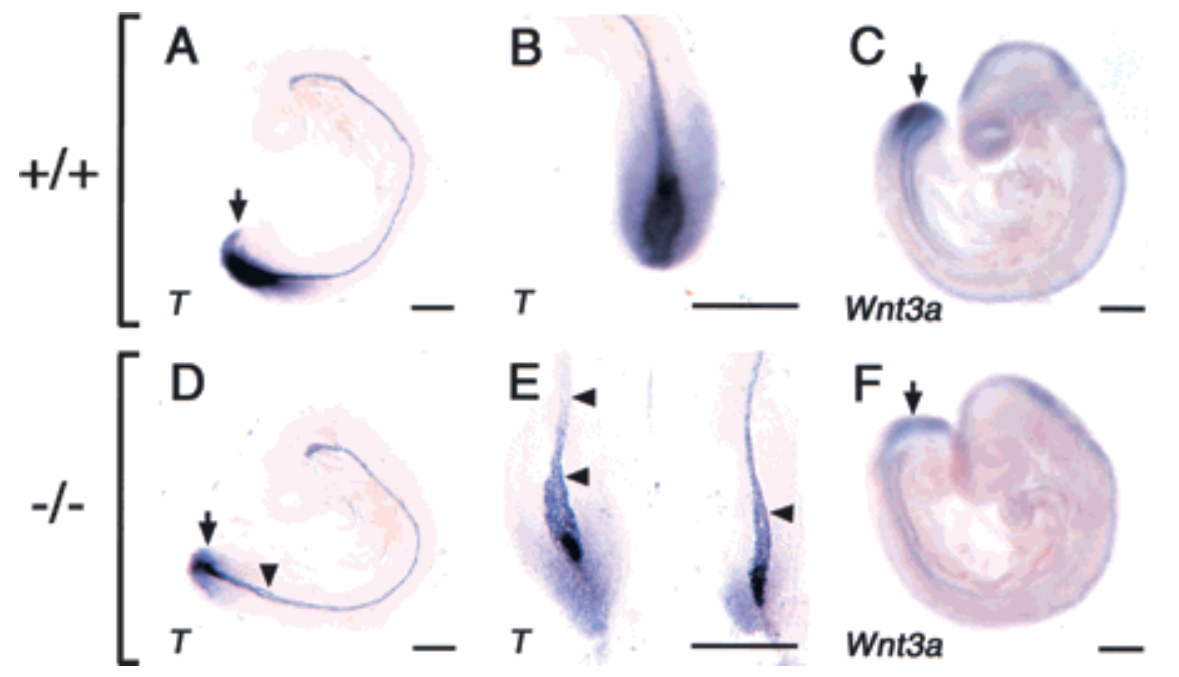

Figure 4. Molecular characterization of caudal truncation in CYP26-/- embryos. $(A, B, D, E)$ Expression of $T$ (Brachyury) in wild-type $(A, B)$ and $C Y P 26^{-/-}(D, E)$ embryos at E9.0. The expression of $T$ is markedly down-regulated in the tailbud of the mutant embryo (arrow). The arrowheads in $D$ and $E$ indicate bifurcation of the notochord. $(C, F)$ Expression of Wnt3a in wild-type and $C Y P 26^{-/-}$embryos, respectively, at E9.0. The expression of Wnt3a is down-regulated in the tailbud of the mutant embryo (arrow). Scale bar, $300 \mu \mathrm{m}$ for $A-F$. 

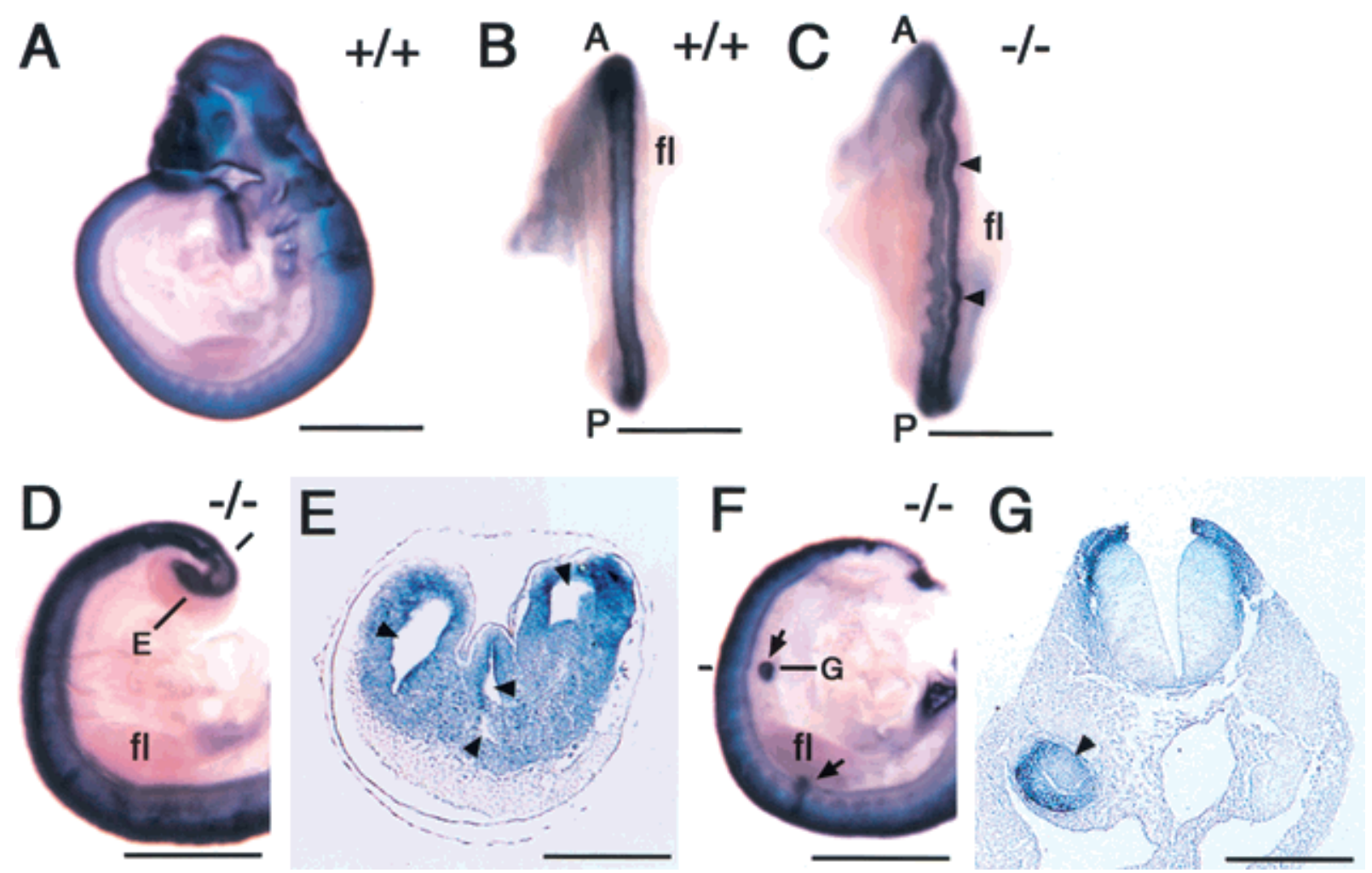

Figure 5. Ectopic neural structures in CYP26 $6^{-/-}$embryos. $(A-G)$ Expression of Sox2 in wild-type $(A, B)$ and $C Y P 26^{-/-}(C-G)$ embryos at E9.5. $(B, C)$ Dorsal view of the neural tube. The arrowheads in $C$ indicate irregular folding of the neural tube. (A) Anterior; $(\mathrm{P})$ posterior; (fl) forelimb. $(D, E)$ Formation of multiple neural tubes. The level of the section shown in $E$ is indicated. The arrowheads in $E$ indicate multiple neural tubes. $(F, G)$ Ectopic neural tube formation. The arrows in $F$ indicate ectopic neural tubes in the trunk. The level of the section shown in $G$ is indicated. The arrowhead in $G$ indicates an ectopic neural tube. Scale bar, $1 \mathrm{~mm}$ for $A-D, F ; 200 \mu \mathrm{m}$ for $E, G$.

tity. The phenotype of the vertebral defects varied among the CYP26 $6^{-1-}$ mice; for example, the mutant mice (5) showed a less severe phenotype (Fig. 6G). However, the posterior transformation of $\mathrm{C} 5-\mathrm{C} 7$ and anterior transformation of L1 were frequently observed.

To gain insight into the vertebral defects, we examined RARE-hsplacZ expression in the trunk region. Wild-type or CYP26-/- embryo harboring RARE-hsplacZ were recovered at E9.5 and E10.5, and were stained with $\mathrm{X}$-gal.

In both the wild-type and mutant embryos, this transgene was expressed in the neural tube with the anterior end of expression domains located in the hindbrain (Figs. 3F-H, 7B, and 9A, below). In the CYP26-/- mice, however, the level of X-gal staining in the neural tube was elevated. Furthermore, the staining in the somites was markedly increased (Fig. 7A,B), and was accompanied by anterior expansion of Hoxb4 expression domains (Fig. 7D,E). Ectopic Hoxb4 expression in the fifth somite may account for the malformation of cervical vertebrae, as the fifth somite eventually contributes to $\mathrm{C} 1$. In the wild-type embryos, CYP26 was found to be expressed in the somites, albeit at a low level (Fig. 7C). Together, these results suggest that aberrant Hox expression in the somites, which is induced by the increase in the concen- tration of RA, is responsible for misspecification of vertebrae.

\section{Increased RA level does not affect forelimb development}

Numerous studies have implicated RA in limb development. In particular, RA may be involved in the zone of polarizing activity. CYP26 is expressed in the forelimb between E9.5 and E11.5 (Fujii et al. 1997). We have examined the level of endogenous RA in the forelimb buds. In the wild-type forelimb bud, RARE-hsplacZ was expressed at a low level between E9.5 (Fig. 8A) and E10.5 (Fig. 8B). At E12.5, RARE-hsplacZ expression was restricted to the interdigital regions (Fig. 8C). In the $\mathrm{CYP}^{-/-}$forelimb, RARE-hsplacZ expression was highly up-regulated at E9.5 (Fig. 8D) but declined to a near normal level at E10.5 (Fig. 8E). At E12.5, RAREhsplac $Z$ expression appeared in the interdigital region at E12.5 (Fig. 8F). These expression patterns of RAREhsplacZ indicates that, in the CYP26 ${ }^{-/-}$forelimb, the level of RA is markedly increased between E9.5 and E10.5. However, genes implicated in limb development were expressed normally in the CYP26 $6^{-/-}$forelimb.

For example, sonic hedgehog (shh), which is expressed in the posterior region of the wild-type forelimb at E10.5 

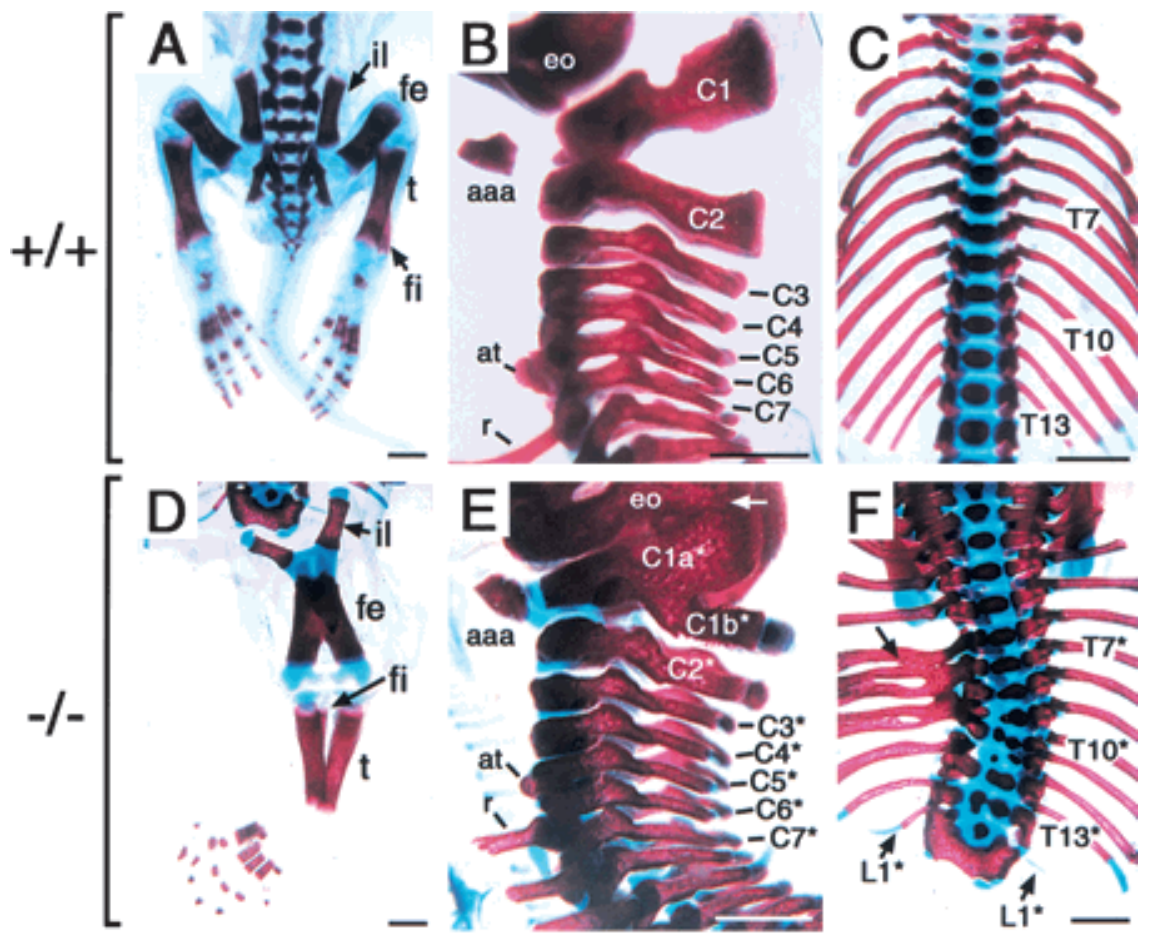

\section{G}

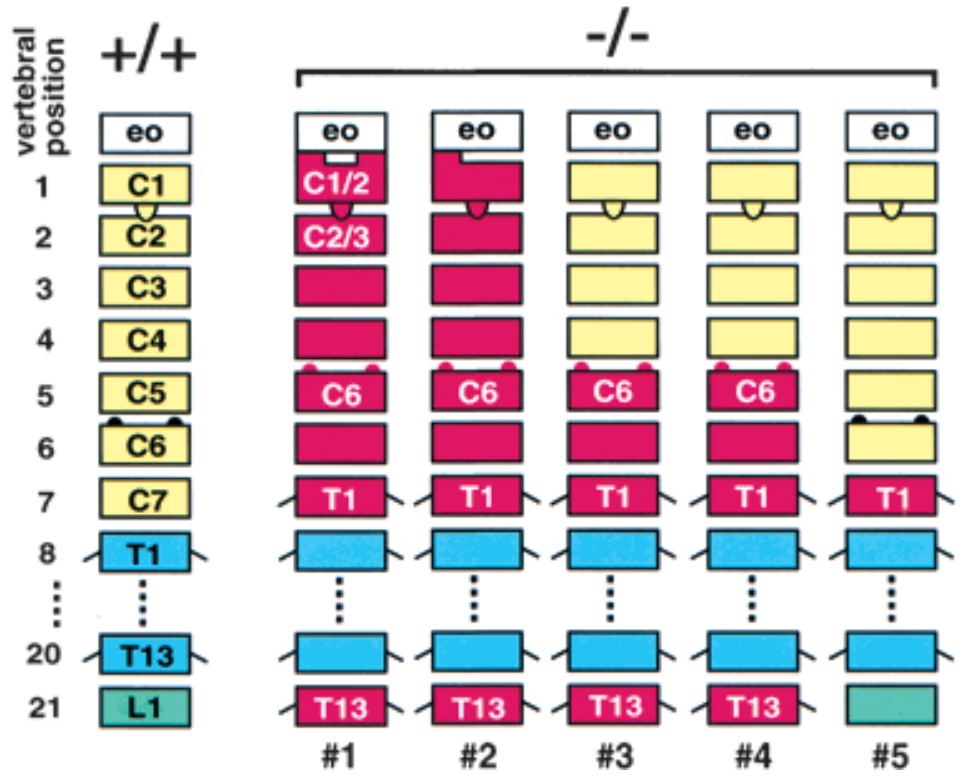

Figure 6. Homeotic transformation of vertebrae. $(A-F)$ Skeletal staining of wild-type $(A-C)$ and $C Y P 26^{-/-}(D-F)$ mice at P1. (il) Ilium; (fe) femur; (t) tibia; (fi) fibula; (aaa) anterior arch of the atlas; (at) anterior tubercle; (r) rib; (eo) exoccipital bone. The cervical vertebrae $\left(\mathrm{C} 1^{\star}-\mathrm{C} 7^{\star}\right)$, thoracic vertebrae $\left(\mathrm{T} 1^{\star}-\mathrm{T} 13^{\star}\right)$, and twenty-first vertebra $\left(\mathrm{L} 1^{\star}\right)$ of the mutant mice are also indicated. The arrow in $E$ indicates fusion of $\mathrm{Cla}^{\star}$ and the exoccipital bone. The arrow in $F$ indicates fusion of ribs. $(G)$ Schematic representation of vertebral transformation. Five CYP26 $6^{-/-}$mutant mice (1-5) were analyzed. Scale bar, $1 \mathrm{~mm}$ for $A-F$.

(Fig. 8G), was expressed normally in the mutant forelimb (Fig. $8 \mathrm{H}$ ). Furthermore, the forelimbs of the CYP26 $6^{-1-}$ newborn mice were morphologically normal (Fig. 2A,B; data not shown).

\section{Hindbrain patterning defects}

RA is also implicated in the patterning of the hindbrain
(Conlon and Rossant 1992; Marshall et al. 1992; Wood et al. 1994; Kolm et al. 1997; van der Wees et al. 1998).

CYP26 is transiently expressed in the prospective rhombomere 2 (pr2) between E8.25 and E9.0 (Fujii et al. 1997), whereas Raldh2 is expressed in the body trunk (spinal cord) (Niederreither et al. 1997). To investigate whether the lack of CYP26 alters the distribution of RA in the hindbrain of $C Y P 26^{-1-}$ embryos, we first examined 

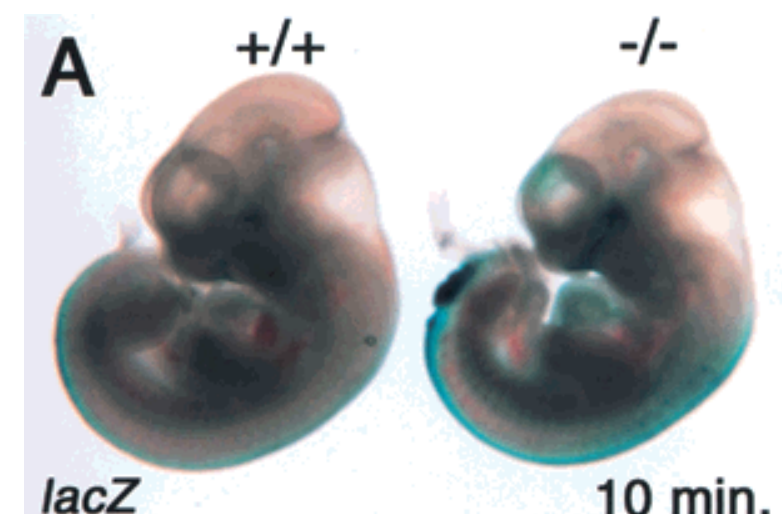

$10 \mathrm{~min}$.
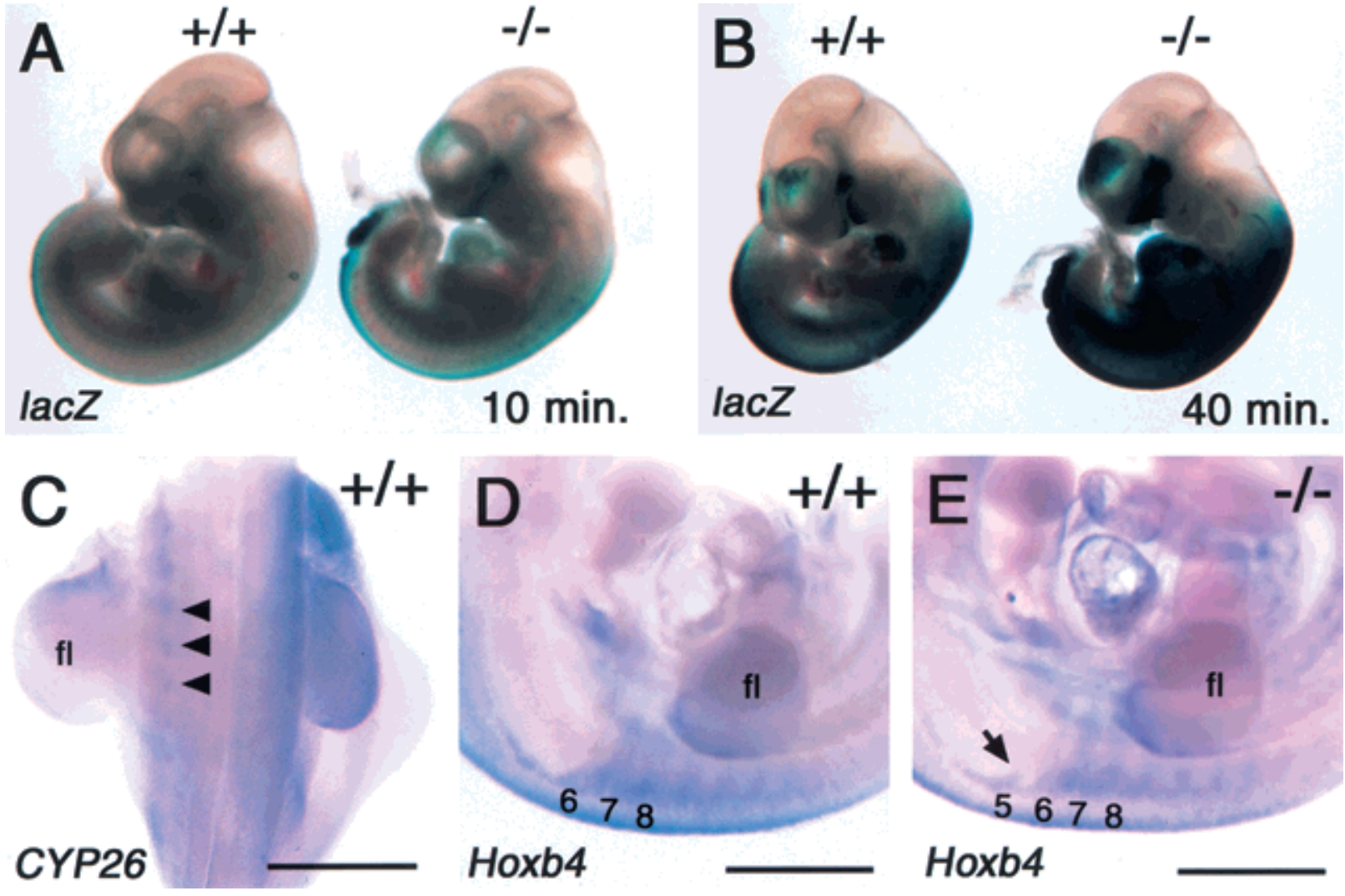

Hoxb4

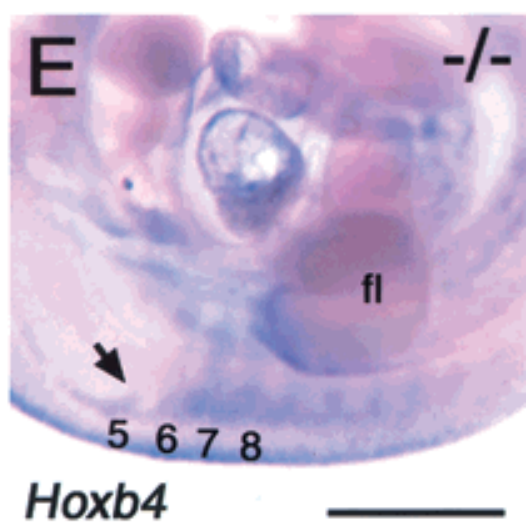

Figure 7. Elevation of RA level and aberrant expression of Hoxb4 in the somites. $(A, B)$ Expression of the RARE-hsplacZ transgene in the wild-type and $C Y P 26^{-/-}$embryos at E10.5. The level of X-gal staining in the trunk was elevated in the $C Y P 26^{-/-}$embryos for various staining time of $10 \mathrm{~min}(A)$ and $40 \mathrm{~min}(B) .(C)$ Expression of CYP26 in the trunk of the wild-type embryos at E10.5. Arrowheads indicate the somites. (fl) Forelimb. $(D, E)$ Expression of the Hoxb4 in the somites of wild-type $(D)$ and $C Y P 26^{-/-}(E)$ embryos at E10.5. The arrow in $E$ indicates ectopic expression of $H o x b 4$ in the fifth somite of the mutant embryo. Scale bar, $1 \mathrm{~mm}$ for $C-E$.

the expression of the RARE-hsplacZ transgene in the hindbrain region at E8.25. In wild-type embryos, the rostral border of X-gal staining was located at the pr3-pr4 boundary (Fig. 9A,K). In CYP26 ${ }^{-/-}$embryos, however, the border of transgene activity was shifted anteriorly to the pr2 ${ }^{\star}-$ pr3 ${ }^{\star}$ boundary (Fig. 9B,K), suggesting that the concentration of RA was increased in pr $3^{\star}$. The hindbrain of CYP26 $6^{-/}$embryos remained morphologically normal at E8.25. However, the increased RA concentration in the rostral hindbrain of $C Y P 26^{-/-}$embryos was accompanied by anterior expansion of the expression domain of the homeotic gene Hoxb1. Whereas Hoxb1 was expressed in pr4 of wild-type embryos at E8.25 (Fig. 9C,K), the Hoxb1 expression domain included $\mathrm{pr} 4^{\star}, \mathrm{pr} 3^{\star}$, and a portion of $\mathrm{pr}^{*}$ in $C Y P 26^{-/-}$embryos at this stage (Fig. 9D,K). The expression of Krox20 was also affected in the mutant embryos. This gene was expressed in two regions of the hindbrain, pr3 and pr5, in wild-type embryos at E8.25 (Fig. 9G,I,K). In CYP26 $6^{-/-}$embryos, however, the rostral expression domain of Krox20 was narrowed and the expression level reduced (Fig. 9H,J,K). At E9.5, when Hoxb1 is expressed in $\mathrm{r} 3$ of the normal hindbrain (Fig. 9E), it was expressed in two discrete regions of the mutant hindbrain, $\mathrm{r}^{\star}{ }^{\star}$ and $\mathrm{r} 4^{\star}$ (Fig. $9 \mathrm{~F}$ ).

Morphological hindbrain defects became apparent in the mutant embryos at E10.5. At this stage, the hindbrain of wild-type embryos exhibits well-defined rhombomeric segmentation (Fig. 9L). Although rhombomeric segments were apparent in $\mathrm{CYP} 26^{-/-}$embryos at this stage, the segmentation pattern was abnormal (Fig. 8M). In particular, $\mathrm{r}^{\star}$ and $\mathrm{r} 3^{*}$ were markedly shortened. Cranial ganglia, which are derived from neural crest cells of the hindbrain, were also abnormal in $\mathrm{CYP}^{-6^{-/}}$embryos.

Whereas the trigeminal (V) and facial (VII) ganglia are separately located in rhombomeric regions 2 and 4, respectively, of wild-type embryos (Fig. 9N), these two ganglia were fused and clustered in the $\mathrm{r} 2^{\star}-\mathrm{r} 3^{\star}-\mathrm{r} 4^{\star}$ region of $\mathrm{CYP}_{26^{-/-}}$embryos (Fig. 9O). These results together suggest that, in CYP26-1- embryos, $\mathrm{r} 2$ and $\mathrm{r} 3$ are reduced in size and $\mathrm{r} 3$ (and, to a lesser extent, $\mathrm{r} 2$ ) is misspecified, adopting an $\mathrm{r} 4$ identity.

\section{Discussion}

In this study, we have examined the role of CYP26 in RA metabolism and in development by generating mutant mice that lack CYP26. Our results indicate that CYP26 functions as an RA-degrading enzyme in vivo, and that CYP26 is required for generating the precise pattern of RA distribution in developing mouse embryos. Similar 


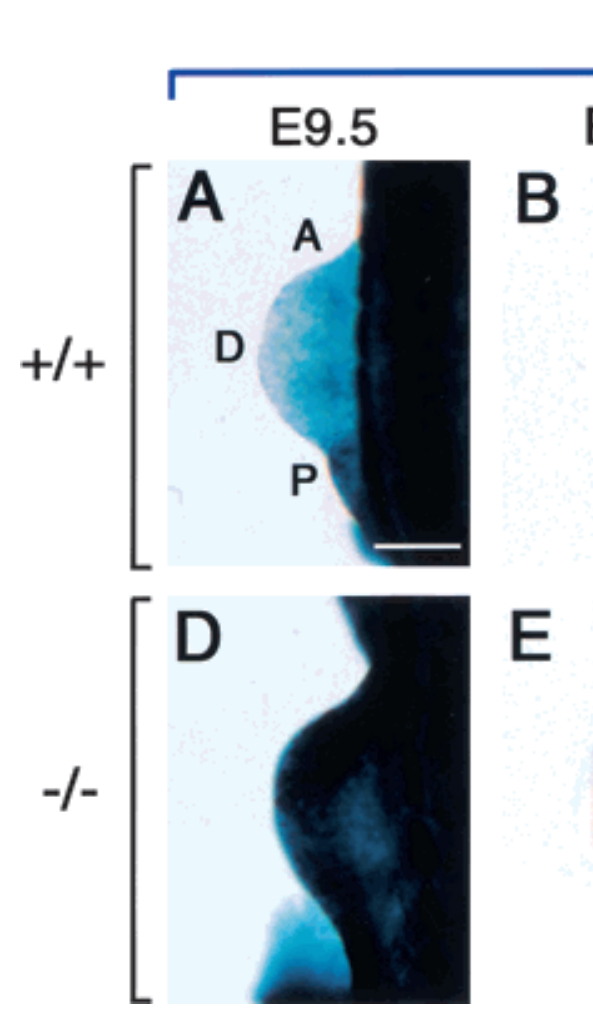

lacZ

E10.5
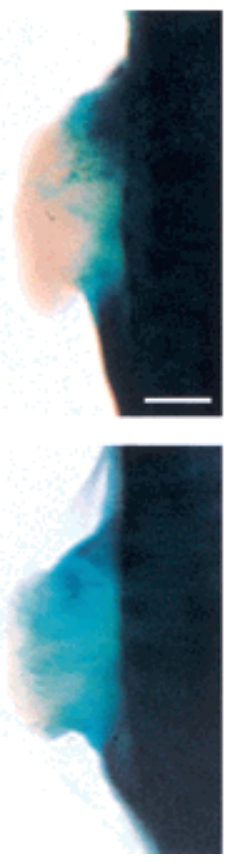

E12.5
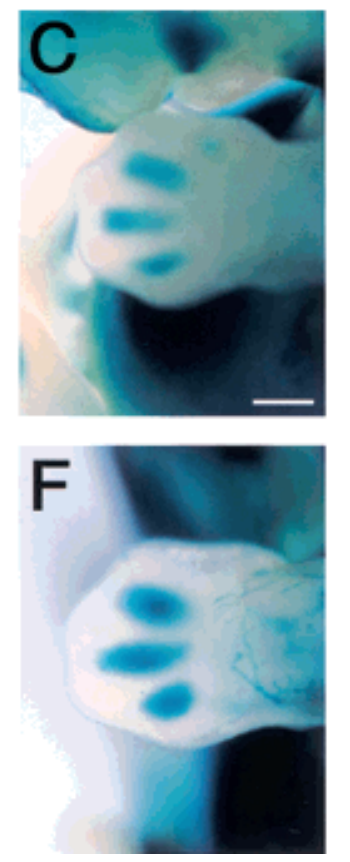

shh
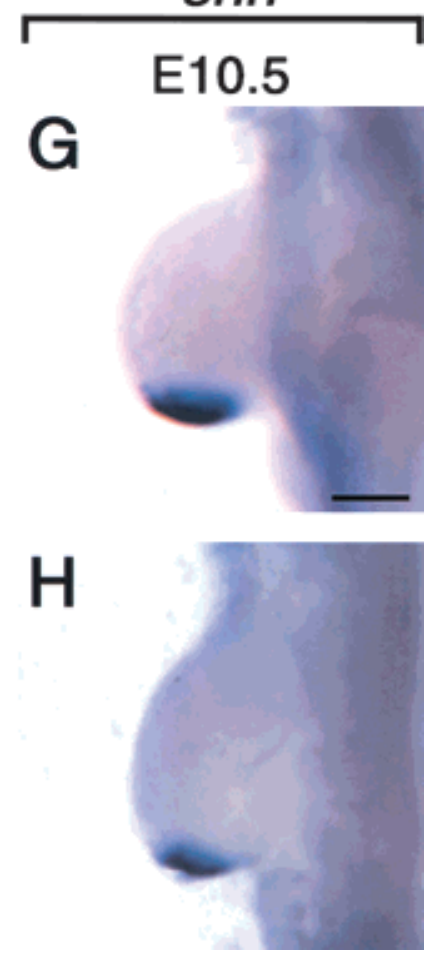

Figure 8. Altered RA level in the developing forelimb. $(A-C)$ Expression of the RARE-hsplacZ transgene in the forelimb bud of the wild-type embryos at 9.5, E10.5, and E12.5, respectively. $(D-F)$, Expression of the RARE-hsplacZ transgene in the forelimb bud of the CYP26 $6^{-/-}$embryos. (A) Anterior; (P) posterior; (D) distal. $(G, H)$ Expression of shh in the forelimb bud of the wild-type $(G)$ and $C Y P 26^{-/-}$ $(H)$ embryos at E10.5. Scale bar, $300 \mu \mathrm{m}$.

results are reported in an accompanying work (Abu-Abed et al. 2001).

\section{CYP26 is an RA-degrading enzyme}

Previous observations that overexpression of CYP26 rendered cells hyposensitive to RA (Fujii et al. 1997), suggested that CYP26 is an RA-inactivating enzyme. CYP26 can metabolize RA into oxidative forms in vitro (Fujii et al. 1997) and in cultured cells (Abu-Abed et al. 1998), but several different products have been reported as metabolic products of CYP26, including 5,8-epoxy RA (Fujii et al. 1997), 4-hydroxy RA, 4-oxo-RA, and 18-hydroxy RA (Abu-Abed et al. 1998). These hydroxylated forms of RA have been reported to possess similar biological activity to RA; 4-oxo RA, in particular, is known to be as potent as RA (Pijnappel et al. 1993). Thus, it has not been established whether CYP26 degrades RA or it converts RA into different forms of active retinoids.

The phenotype of the CYP26 $6^{-/-}$mice now strongly supports a notion that CYP26 metabolizes RA into inactive forms. First, there was an inverse correlation between the level of active RA and the level of CYP26 expression; the level of endogenous RA (as visualized by the RARE-hsplacZ transgene) was markedly elevated in the tailbud and hindbrain in which CYP26 is normally expressed. Second, most of the malformations seen in the CYP26 $6^{-/-}$mouse are those induced by excess RA.
Thus, similar caudal truncation, vertebral transformation, and hindbrain defects to those apparent in CYP26 $6^{-1-}$ mouse embryos have been observed in rodent embryos treated with excess RA (Shenefelt 1972; Tibbles and Wiley 1988).

Finally, some of the characteristics of Raldh2 mutants are opposite to those of CYP26 mutants; for example, the caudal hindbrain is anteriorized in Raldh2 mutants (Niederreither et al. 2000), whereas the rostral hindbrain is posteriorized in CYP26 mutants. The phenotype of CYP26 mutant mice is therefore consistent with the previous observation (Fujii et al. 1997) that CYP26 metabolically inactivates RA (although we cannot rigorously exclude the alternative possibility because RARE-hsplac $Z$ may not respond to all types of active retinoids).

\section{CYP26 establishes an uneven distribution of RA in developing embryos}

It is generally accepted that RA is unevenly distributed in a developing embryo.

However, the precise pattern of RA distribution in developing embryos is not certain. Classical theories have suggested that RA is a posteriorizing factor with a high point at the posterior end and a decreasing gradient toward the anterior end. However, many lines of recent evidence have suggested that this type of gradient is not the case. For instance, the study on the distribution of 
Sakai et al.

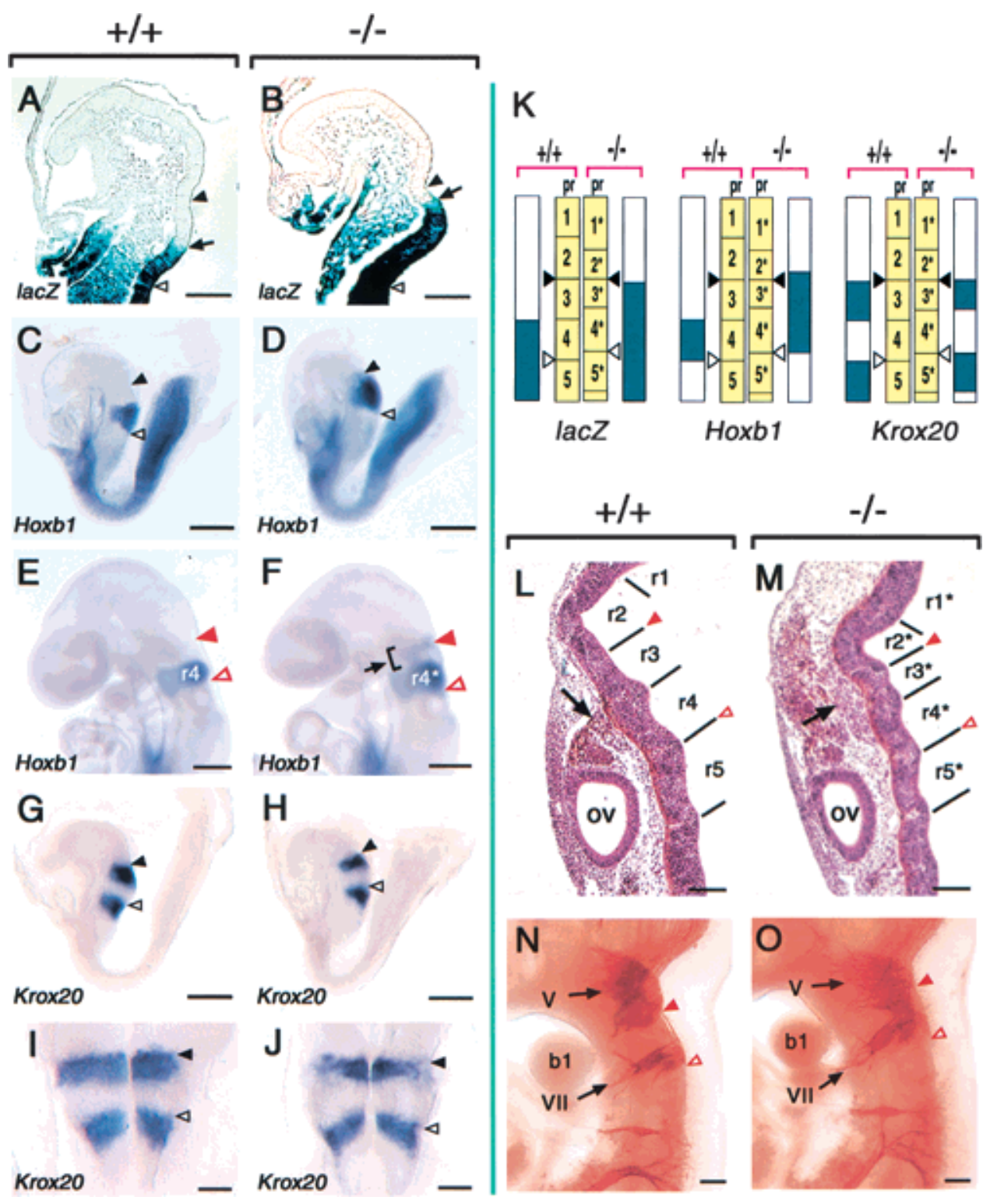

Figure 9. Rostral hindbrain defects in $C Y P 26^{-/-}$embryos. $(A, B)$ Expression of the RARE-hsplacZ transgene in the hindbrain of wild-type $(A)$ and $C Y P 26^{-I-}(B)$ embryos at E8.25. The arrow indicates the rostral boundary of X-gal staining. (C-F) Expression of Hoxb1 in wild-type $(C, E)$ and $C Y P 26^{-/-}(D, F)$ embryos at E8.25 $(C, D)$ and E9.5 $(E, F)$. The arrow in $F$ indicates ectopic expression of $H o x b 1$ in r3* of the mutant embryo. $(G-J)$ Expression of Krox20 in wild-type $(G, I)$ and CYP26 ${ }^{-/}(H, J)$ embryos at E8.25. (K) Schematic representation of the expression domains of RARE-hsplacZ, Hoxb1, and Krox20 at E8.25. (pr) Prospective rhombomere. (L,M) Sagittal sections of the hindbrain of wild-type and $C Y P 26^{-1-}$ embryos, respectively, at E10.5. Rhombomere segments are referred to as r1 to r5 in the wild-type embryo and as $\mathrm{r}^{\star}{ }^{\star}$ to $5^{\star}$ in the mutant embryo. In the $C Y P 26^{-1-}$ embryo, cranial neural crest cells (arrow) are located in the region of $\mathrm{r}^{\star}$ to $\mathrm{r}^{\star}{ }^{\star}$. (ov) Otic vesicle. $(N, \mathrm{O})$ Cranial nerves in wild-type and CYP26 $6^{-/}$embryos, respectively, at E10.5. The nerves were detected with an antibody to neurofilaments. (b1) First branchial arch; (V) fifth (trigeminal) ganglia; (VII) seventh (facial) ganglia. Closed black and open black arrowheads in E8.25 embryos indicate the preotic sulcus and otic sulcus, respectively. Closed red and open red arrowheads in E9.5 and E10.5 embryos indicate the r2-r3 (or r2 ${ }^{\star}-\mathrm{r} 3^{\star}$ ) boundary and the r4-r5 (or r4 ${ }^{\star}-\mathrm{r} 5^{\star}$ ) boundary, respectively. Scale bar, $100 \mu \mathrm{m}$ for $A, B, I, J$, and $L-O ; 300 \mu \mathrm{m}$ for $C-H$.

RA by a F9 reporter cell line (Maden et al. 1998) suggests that there may be a sharp border of RA production at the head/trunk junction and a decline toward the caudal end.

It is now conceivable that the distribution of RA within an embryo at a given stage is determined by the expression profiles of Raldh2 and CYP26.

Diffusion of RA itself may also contribute to its dis- tribution pattern because RA may travel over a long distance (in fact, RA activity has been detected in sites in which Raldh2 is not expressed). Our data also support long-range diffusion of RA.

Thus, RA-containing regions (detected by RAREhsplacZ expression) greatly exceeded the regions expressing Raldh2 in CYP26 ${ }^{-/-}$embryos (the expression 
pattern of Raldh2 was not altered in the mutant embryo; data not shown).

The phenotype of the CYP26 mutant mice indicate that CYP26, together with Raldh2, establishes an uneven distribution of RA along the A-P axis in developing embryos.

On the basis of the present data and previous observations made on the expression patterns of CYP26 and Raldh2 (Fujii et al. 1997; Niederreither et al. 1997) and on the Raldh2 mutant mice (Niederreither et al. 1999, 2000), we propose a model for RA distribution in the developing mouse embryo. In the anterior region, CYP26 is expressed in the rostral hindbrain (pr2) (Fujii et al. 1997; Iulianella et al. 1999), whereas Raldh2 expression domains extend to the head/trunk junction (Niederreither et al. 1997; Swindell et al. 1999). Such complementary localizations of RA-synthesizing and RA-degrading activities may generate a sharp boundary of RA concentration within the hindbrain. Such a boundary of RA may be required for the precise segmentation of the hindbrain. In the absence of CYP26, the boundary of RA in the hindbrain would shift anteriorly or a leaky gradient of RA may occur instead of a sharp boundary, which would result in posterior transformation of hindbrain (pr3).

CYP26 may also generate a sharp boundary of RA in the caudal region. This can keep the level of RA in the tailbud low (as measured by RARE-hsplacZ) and may permit tailbud mesoderm cells to proliferate properly. It has been shown that Wnt $a$ and Brachury are required for the development of caudal structures (Wilkinson et al. 1990; Takada et al. 1994; Yamaguchi et al. 1999|, and that both genes are down-regulated by excess RA (Iulianella et al. 1999). In the CYP26 ${ }^{-/}$embryos, a higher level of RA in the taildbud may have impaired the proliferation of mesoderm cells and have transformed mesoderm into neural fates. The lack of CYP26 may have generated a leaky gradient declining toward the caudal end (instead of a sharp boundary), which would explain why the twenty-first vertebra (L1) was anteriorly transformed in the CYP26-/- mice.

In the trunk region, there may be a gradient gradually increasing toward the caudal end, which specifies the identity of cervical and thoracic vertebrae. This model is consistent with the vertebral defects observed in the CYP26 $6^{-/}$mice; if the lack of CYP26 shifts up the RA gradient, cervical vertebrae would undergo posterior transformation. The CYP26-/- mice showed posterior transformation of cervical vertebrae (associated with anterior expansion of Hoxb1 expression).

At the early streak stage (E7.5 in the mouse), CYP26 and Raldh2 exhibit strikingly complementary expression; CYP26 expression is confined to the anterior region, whereas Raldh2 expression is confined to the posterior region. However, A-P patterning at this stage does not seem to require Raldh2 or CYP26 because expression of Hoxa1 (a posterior gene) and Otx2 (an anterior gene) at E7.5/E7.75 remained rather normal in Raldh2 mutants (Niederreither et al. 1999) and in CYP26 mutants (data not shown). Thus, RA does not seem to have the major role in A-P patterning at the streak stage.
CYP26 may establish an uneven distribution of RA within local organs as well. For example, CYP26 is expressed in the dorso-ventral boundary region of the neural retina, and may play a role in specifying retinal neurons. Although the retina of $C Y P 26^{-/-}$mice appeared morphologically normal, patterning and projection of the retinal neurons needs to be studied. CYP26 is also expressed in developing limbs (Fujii et al. 1997). There have been numerous studies that implicate RA in specifying the zone of polarizing activity (ZPA), a signaling center in the limb bud. In the CYP26 mutant embryos, the level of RA was dramatically elevated in the forelimb bud at E9.5. Therefore, it was surprising that the mutant forelimb developed normally. However, this does not exclude the role of RA in limb patterning, because the level of RA in the forelimb increased only transiently (returned to the normal level at E12.5). The role of RA in limb development needs to be examined further, such as by generating conditional Raldh2 mutant mice.

\section{Materials and methods}

Generation of CYP26 mutant mice

CYP26 clones were isolated from a genomic library constructed from E14 embryonic stem (ES) cells. A targeting vector was constructed by subcloning the 5 '-flanking region (the 7-kb SalIClaI fragment), the exon-intron region (the $5.5-\mathrm{kb} \mathrm{ClaI}-\mathrm{XhoI}$ fragment), and the $3^{\prime}$-flanking region (the $4.5-\mathrm{kb}$ Xhol fragment) of CYP26 into a modified pMC1-DTpA vector (Taniguchi et al. 1997). A lox P fragment containing a ClaI site was inserted into the $5^{\prime}$-untranslated region, and a lox P-neo cassette was inserted into the XhoI site in the $3^{\prime}$-flanking region. Gene targeting was performed as described previously (Sawai et al. 1991). The targeting vector was linearized with NsiI before introduction by electroporation into R1 ES cells.

Of 133 G418-resistant ES clones, one (R19) was shown to have undergone homologous recombination, which was confirmed by Southern blot analysis with various probes including a $5^{\prime}$ probe, a $3^{\prime}$ probe, and a neo probe. To generate a null allele, we subjected R19 cells to electroporation with a Cre expression vector (pCre-Pac; Taniguchi et al. 1997) followed by selection with puromycin $(1 \mu \mathrm{g} / \mathrm{mL}$; Sigma). Cre-mediated deletion was verified by PCR and Southern blot analysis. PCR was performed with the primers P1 (5'-GGTAACGTGGGCAGTAACCTG), P2 (5'-TCCATGAGCCGAGTTCTGTAG), and P3 (5'-TCC GTTCAGTCAGTCTCATAC). One clone (R19-R93) that was shown to have lost the CYP26 exons was used in this study. R19 or R19-R93 cells were injected into blastocysts obtained from the mating of $\mathrm{C} 57 \mathrm{BL} / 6 \mathrm{Cr}$ mice with $(\mathrm{C} 57 \mathrm{BL} / 6 \mathrm{Cr} \times \mathrm{DBA}) \mathrm{F}_{1}$ mice, resulting in the birth of chimeric animals. Male chimeras derived from each ES cell line were bred with C57BL/6Cr females, yielding heterozygous $\mathrm{F}_{1}$ offspring. The $\mathrm{F}_{1}$ heterozygotes were mated with each other, producing $C Y P 26^{\text {neo/neo }}$ and CYP26 ${ }^{-/-}$mice.

\section{Analysis of CYP26 mutant mice}

All mice were bred with NMF (Oriental Yeast Company), which contains 29 IU of vitamin A (as retinol) per gram. Embryos were genotyped by PCR analysis of yolk sac or tail DNA. Wholemount in situ hybridization was performed according to standard protocols (Wilkinson 1992). Assignment of axial level in 
whole-mount embryos was performed as described previously (Burke et al. 1995). For histological analysis, embryos were fixed in Bouin's fixative, dehydrated, and embedded in paraffin. Serial

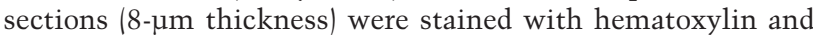
eosin according to standard procedures. Skeletal staining was performed as described previously (Kessel and Gruss 1991). A monoclonal antibody to neurofilaments (2H3; Developmental Studies Hybridoma Bank, Iowa University) was used for wholemount detection of cranial nerves (Taniguchi et al. 1997). Staining was developed with $p$-dimethylaminoazobenzene. Transgenic mice harboring a RARE-hsplacZ transgene (Rossant et al. 1991) were mated with $C Y P 26^{+/-}$mice to obtain $C Y P 26^{+/-}$animals positive for the transgene; these animals were then crossed with $\mathrm{CYP26^{+/- }}$ mice, and the resulting embryos were subjected to genotyping and staining with 5-bromo-4-chloro-3-indoyl- $\beta$ D-galactoside (X-gal).

\section{Acknowledgments}

We thank A. Nagy and H. Kondoh for R1 ES cells; P. McCaffery, A. McMahon, E. Robertson, O. Chisaka, H. Koseki, T. Nagase, N. Ohsumi, T. Kondoh, D. Duboule, T. Ogura, and N. Takahashi for in situ hybridization probes; T. Yagi for pMC1-DTpA and pCre-Pac; J.-I. Miyazaki, H. Kondoh, P. McCaffery, and members of the Hamada laboratory for helpful suggestions. This work was supported by CREST of the Japan Science and Technology Corporation, and by Grants-in-Aid for Scientific Research from the Ministry of Education, Science, Sports, and Culture of Japan.

The publication costs of this article were defrayed in part by payment of page charges. This article must therefore be hereby marked "advertisement" in accordance with 18 USC section 1734 solely to indicate this fact.

\section{References}

Abu-Abed, S.S., Beckett, B.R., Chiba, H., Chithalen, J.V., Jones, G., Metzger, D., Chambon, P., and Petkovich, M. 1998. Mouse P450RAI (CYP26) expression and retinoic acid-inducible retinoic acid metabolism in F9 cells are regulated by retinoic acid receptor $\gamma$ and retinoid $\mathrm{X} \alpha$. J. Biol. Chem. 273: 2409-2415.

Burke, A.C., Nelson, C.E., Morgan, B.A., and Tabin, C. 1995 Hox genes and the evolution of vertebrate axial morphology. Development 121: 333-346.

Chen, Y., Huang, L., Russo, A.F., and Solursh, M. 1992. Retinoic acid is enriched in Hensen's node and is developmentally regulated in the early chick embryos. Proc. Natl. Acad. Sci..89: 10056-10059.

Conlon, R.A. 1995. Retinoic acid and pattern formation in vertebrates. Trends Genet. 11: 314-319.

Conlon, R.A. and Rossant, J. 1992. Exogenous retinoic acid rapidly induced anterior ectopic expression of murine Hox-2 gene in vivo. Development 116: 357-368.

Fujii, H., Sato, T., Kaneko, S., Gotoh, O., Fujii-Kuriyama, Y., Osawa, K., Kato, S., and Hamada, H. 1997. Metabolic inactivation of retinoic acid by a novel $\mathrm{P} 450$ differentially expressed in developing mouse embryos. EMBO J. 16: 41634173.

Helms, J.A., Kim, C.H., Eichele, G., and Thaller, C. 1996. Retinoic acid signaling is required during early chick limb development. Development 122: 1385-1394.

Hollemann, T., Chen, Y., Grunz, H., and Pieler, T. 1998. Regionalized metabolic activity establishes boundaries of reti- noic acid signalling. EMBO J. 17: 7361-7373.

Iulianella, A., Beckett, B., Petkovich, M., and Lohnes, D. 1999. A molecular basis for retinoic acid-induced axial truncation. Dev. Biol. 205: 33-48.

Kamachi, Y., Uchikawa, M., Collignon, J., Lovell-Badge, R., and Kondoh, H. 1998. Involvement of Sox 1, 2 and 3 in the early and subsequent molecular events of lens induction. Development 125: 2521-2532.

Kastner, P., Mark, M., and Chambon, P. 1995. Nonsteroid nuclear receptors: What are genetic studies telling us about their role in real life? Cell 83: 859-869.

Kessel, M. and Gruss, P. 1991. Homeotic transformations of murine vertebrae and concomitant alteration of Hox codes induced by retinoic acid. Cell 67: 89-104.

Kolm, P.J., Apekin, V., and Sive, H. 1997. Xenopus hindbrain patterning requires retinoid signaling. Dev. Biol. 192: 1-16.

Maden, M. 1999. Heads or tails? Retinoic acid will decide. Bioessays 21: 809-812.

Maden, M., Sonneveld, E., van der Saag, P.T., and Gale, E. 1998. The distribution of endogenous retinoic acid in the chick embryo: Implication for developmental mechanisms. Development 125: 133-144.

Marshall, H., Nonchev, S., Sham, M.H., Muchamore, I., Lumsden, A., and Krumlauf, R. 1992. Retinoic acid alters hindbrain Hox code and induces transformation of rhombomere 2/3 into a 4/5 identity. Nature 360: 737-741.

McCaffery, P., Wagner, E., O'Neil, J., Petkovich, M., and Dräger, U.C. 1999. Dorsal and ventral territories defined by retinoic acid synthesis, break-down and nuclear receptor expression. Mech. Dev. 82: 119-130.

Niederreither, K., McCaffery, P., Dräger, U.C., Chambon, P., and Dollé, P. 1997. Restricted expression and retinoic acidinduced downregulation of the retinaldehyde dehydrogenase type 2 (RALDH-2) gene during mouse development. Mech. Dev. 62: 67-78.

Niederreither, K., Subbarayan, V., Dollé, P., and Chambon, P. 1999. Embryonic retinoic acid synthesis is essential for early mouse post-implantation development. Nature Genet. 21: $444-448$.

Niederreither, K., Vermot, J., Schuhbaur, B., Chambon, P., and Dollé, P. 2000. Retinoic acid synthesis and hindbrain patterning in the mouse embryo. Development 127: 75-85.

Pijnappel, W.W., Hendricks, H.F., Folkers, G.E., van den Brink, C.E., Edelenbosch, E.J., van der Saag, P.T., and Durston, A.J. 1993. The retinoid ligand 4-oxo retinoic acid is a highly active modulator of positional specification. Nature 366: 340 344.

Ray, W.J., Bain, G., Yao, M., and Gottlieb, D.I. 1997. CYP26, a novel mammalian cytochrome $\mathrm{P} 450$, is induced by retinoic acid and defines a new family. J. Biol. Chem. 272: 18702 18708.

Rossant, J., Zirngibl, R., Cado, D., Shago, M., and Gigùere, V. 1991. Expression of a retinoic acid responsive elementhsplacZ transgene defines specific domains of transcriptional activity during mouse embryogenesis. Genes \& Dev. 5: 1333-1344

Sawai, S., Shimono, A., Hanaoka, K., and Kondoh, H. 1991. Embryonic lethality resulting from disruption of both $\mathrm{N}$-myc alleles in mouse zygotes. New Biologist 9: 861-869.

Shenefelt, R.E. 1972. Morphogenesis of malformations in hamsters caused by retinoic acid: Relation to dose and stage at treatment. Teratology 5: 103-118.

Sockanathan, S. and Jessell, T.M. 1998. Motor neuron-derived retinoid signaling specifies the subtype identity of spinal motor neurons. Cell 84: 503-514.

Swindell, E.C., Thaller, C., Sockanathan, S., Petkovich, M., Jes- 
sel, T.M., and Eichele, G. 1999. Complementary domains of retinoic acid production and degradation in the early chick embryo. Dev. Biol. 216: 282-296.

Takada, S., Stark, K.L., Shea, M.J., Vassileva, G., McMahon, J.A., and McMahon, A.P. 1994. Wnt-3a regulates somite and tailbud formation in the mouse embryo. Genes \& Dev. 8: $174-189$.

Taniguchi, M., Yuasa, S., Fujisawa, H., Naruse, I., Saga, S., Mishima, M., and Yagi, T. 1997. Disruption of Semaphorin $I I I / D$ gene causes severe abnormality in peripheral nerve projection. Neuron 19: 519-530.

Tibbles, L. and Wiley, M.J. 1988. A comparative study of the effects of retinoic acid given during the critical period for inducing spina bifida in mice and hamsters. Teratology 37: 113-125.

van der Wees, J., Schilthuis, J.G., Koster, C.H., Diesveld-Schipper, H., Folkers, G.E., van der Saag, P.T., Dawson, M.I., Shudo, K., van der Burg, B., and Durston, A.J. 1998. Inhibition of retinoic acid receptor-mediated signalling alters positional identity in the developing hindbrain. Development 125: $545-556$.

Wang, X., Penzes, P., and Napoli, J.L. 1996. Cloning of a cDNA encoding an aldehyde dehydrogenase and its expression in $E$. coli. J. Biol. Chem. 271: 16288-16293.

Wasiak, S. and Lohnes, D. 1999. Retinoic acid affects left-right patterning. Dev. Biol. 215: 332-342.

White, J.A., Guo, Y-D., Baetz, K., Beckett-Jones, B., Bonasoro, J., Hsu, K.E., Dilworth, F.J., Jones, G., and Petkovich, M. 1996. Identification of the retinoic acid-inducible all-trans retinoic acid 4-hydroxylase. J. Biol. Chem. 271: 29922-29927.

Wilkinson, D.G. 1992. Whole mount in situ hybridization of vertebrate embryos. In In situ hybridization: A practical approach. (ed. D.G. Wilkinson), pp. 75-84. IRL Press, Oxford, UK.

Wilkinson, D.G., Bhatt, S., and Herrmann, B.G. 1990. Expression pattern of the mouse $\mathrm{T}$ gene and its role in mesoderm formation. Nature 343: 657-659.

Wood, H., Pall, G., and Morriss-Kay, G. 1994. Exposure to retinoic acid before or after the onset of somitogenesis reveals separate effects on rhombomeric segmentation and 3' HoxB gene expression domains. Development 120: 2279-2285.

Wood, H.B. and Episkopou, V. 1999. Comparative expression of the mouse Sox1, Sox2 and Sox3 genes from pre gastrulation to early somite stages. Mech. Dev. 86: 197-201.

Yamaguchi, T. P., Takada, S., Yoshioka, Y., Wu, N., and McMahon, A.P. 1999. T (Brachyury) is a direct target of Wnt3a during paraxial mesoderm specification. Genes \& Dev. 13: 3185-3190.

Yoshikawa, Y., Fujimori, T., McMahon, A.P., and Takada, S. 1997. Evidence that absence of Wnt-3a signaling promotes neuralization instead of paraxial mesoderm development in the mouse. Dev. Biol. 183: 234-242.

Zhao, D., McCaffery, P., Ivins, K.J., Neve, R.L., Hogan, P., Chin, W.W., and Dräger, U.C. 1996. Molecular identification of a major retinoic-acid-synthesizing enzyme, a retinaldehydespecific dehydrogenase. Eur. J. Biochem. 240: 15-22. 


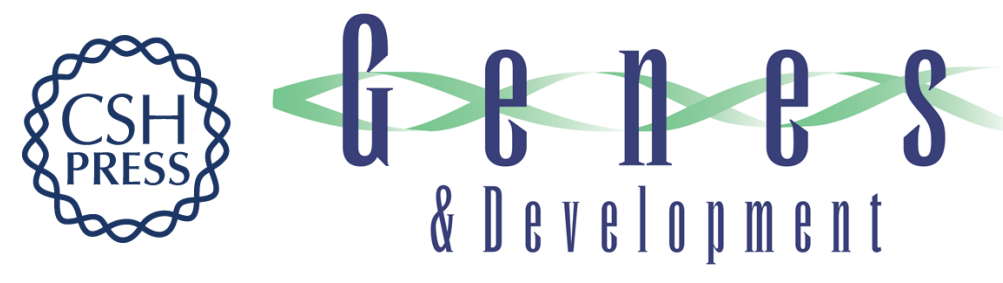

\section{The retinoic acid-inactivating enzyme CYP26 is essential for establishing an uneven distribution of retinoic acid along the anterio-posterior axis within the mouse embryo}

Yasuo Sakai, Chikara Meno, Hideta Fujii, et al.

Genes Dev. 2001, 15:

Access the most recent version at doi:10.1101/gad.851501

\section{License}

Email Alerting Receive free email alerts when new articles cite this article - sign up in the box at the top Service right corner of the article or click here.

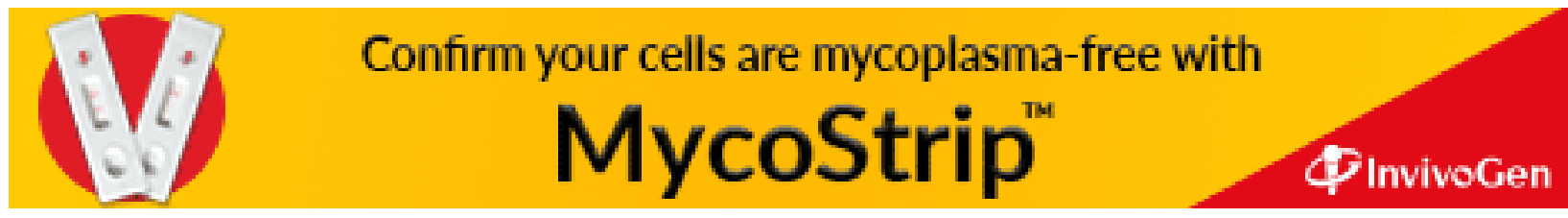

